\title{
Characterization of Copper Complex Nanoparticles synthesized by
}

\section{Plant Polyphenols}

Zhiqiang Wang ${ }^{1,2 *}$, Pengfei $\mathrm{An}^{3}$

1. Research Centre for Soil Contamination Control and Remediation, Chongqing, China

2. China Merchants Group Ecological and Environmental Technologies Co., Ltd

3. Institute of High Energy Physics Chinese Academy of Sciences

*Fax: +86-23-62653335 E-mail: wangzhiqiang2@cmhk.com;

wanzy063@mymail.unisa.edu.au

KEYWORDS: Copper nanoparticle; Green synthesis; Copper complex; Characterization;

Plant polyphenol 


\section{Abstract}

In this paper a kind of copper oxide material of copper-polyphenols complex nanoparticles ( $\mathrm{Cu}-\mathrm{P}$ NPs) were synthesized by Cinnamomum pedunculatum leaves extract, which have different morphology and appearance compared with usual copper oxides $\mathrm{Cu}_{2} \mathrm{O}$ and $\mathrm{CuO}$. For better understanding about this material, the $\mathrm{Cu}-\mathrm{P}$ NPs were characterized using scanning electron microscopy (SEM), X-ray absorption spectroscopy (XAS), X-ray diffraction (XRD), Fourier transform infrared spectroscopy (FTIR), and thermogravimetric analysis (TGA). It was found that synthesized $\mathrm{Cu}-\mathrm{P}$ NPs were amorphous with spherical particles ranged from 80 to $500 \mathrm{~nm}$. XAS data analysis indicated that the synthesized $\mathrm{Cu}-\mathrm{P}$ NPs has different molecular structure with $\mathrm{Cu}_{2} \mathrm{O}$ and $\mathrm{CuO}$. It is assumed that the copper ions chelated with polyphenol molecule. The nanoparticles showed a clear anti Escherichia coli activity in this study, and may also be used in fields of semiconductor, ceramic, catalyst, and sensor. This synthesis approach provided a novel route to manufacture copper oxide nanomaterial. 


\section{Introduction}

Copper oxide nanoparticles can be used as catalysts for reduction, oxidation, electrocatalysis, photocatalysis, and gas-phase reaction [1]. Various physical and chemical methods have been extensively used to produce copper oxide nanoparticles such as chemical treatment, microemulsion method, arc-submerged nanoparticle synthesis system, flame-based aerosol methods, sonochemcial, hydrothermal and solid-state techniques [2-5]. Chemical treatment is regarded more usual methods providing advantages in terms of shape and/or size selectivity. These methods apply toxic chemicals or require high energy usually. Therefore, development of clean, biocompatible, ecofriendly methods for nanoparticles synthesis deserve merit. Review of literature revealed that there are only a very few literatures reported on the use of yeast, fungi, bacteria or plant extract for synthesizing copper oxide NPs [6-10]. However, there is still some ambiguity about the binding structures between organic matter and chelated $\mathrm{Cu}^{2+}$ ions. In 2013, our study [11] reported iron-polyphenols NPs' molecular structure by using XAS analysis, revealed that trivalent iron ions can chelated with oxygen atoms of plant polyphenols to form nanoparticles. Therefore, we would like to investigate copperpolyphenols NPs using XAS again to determine their molecular structure at atom level. And also some studies of the coordination environment of $\mathrm{Cu}^{2+}$ ions in a mixture with polyphenols, probed using SEM, XRD, FTIR, and TGA have been done. It was found the 
mixture of copper salt solution with plant leaves extract leads to formation of copperpolyphenol complex nanoparticles, whose appearance and characters are different from either the reagent copper sulfate or conventional copper oxides.

\section{Material and methods}

Synthesis of Copper-Polyphenol Complex NPs. The plant leaves extract was prepared with the method we used before [12], by heating 200 g Cinnamomum pedunculatum leaves (collected from Nanshan botanical garden Chongqing, China) added to $1000 \mathrm{~mL}$ Milli-Q water at $60{ }^{\circ} \mathrm{C}$ for $2 \mathrm{~h}$. After settling for $0.5 \mathrm{~h}$, the extract was vacuum-filtered. A solution of $0.10 \mathrm{M} \mathrm{CuSO}_{4}$ was prepared by adding $250 \mathrm{~g}$ of $\mathrm{CuSO}_{4} \bullet 5 \mathrm{H}_{2} \mathrm{O}$ (SigmaAldrich) in 1.0 L of Milli-Q water, and subsequently the leaf extract was added to $0.1 \mathrm{M}$ $\mathrm{CuSO}_{4}$ solution in 1:1 ratio in volume. The formation of copper containing NPs was marked by the appearance of a yellowish brown colour. The NPs were separated by centrifuging at $4000 \mathrm{rpm}$ and dried in open air for 24 hours.

\section{Characterizations and Measurements.}

Scanning Electron Microscopy. Morphological characteristics were analysed using a Field Emission-Scanning electron microscope (FE-SEM), specifically an FEI Instruments-Quanta-450-FEG. 
XAS Data Collection. X-ray absorption spectroscopy (XAS) experiments were performed at the Beijing Synchrotron Radiation facility (BSRF). The storage ring operates at $1.5 \mathrm{GeV}$ and a typical current of $200 \mathrm{~mA}$. A Si(111) double crystal was employed as a monochromator. Data were acquired in transmission mode. The ionization chamber was filled with an $\mathrm{N}_{2}$ gas.

XAS Data analysis. XANES spectra were normalized to an edge jump of unity taking into account the atomic background after the edge as it comes out from the EXAFS analysis. Prior removal of the background absorption was done by subtraction of a linear function extrapolated from the pre-edge region. XAS analysis has been performed by using the Athena and Artemis package [13] that takes into account the multiple scattering theory. The method allows the direct comparison of the raw experimental data with a model theoretical signal.

X-ray Diffraction. XRD patterns of $\mathrm{Cu}-\mathrm{P}$ NPs samples were obtained using a Philips PANalytical-Empyrean instrument. The source consisted of $\mathrm{Cu} \mathrm{K \alpha}$ radiation $(\lambda=1.54 \AA)$. Each sample was dried in an open area for $24 \mathrm{~h}$ and then scanned in the $2 \theta$ range of 10 $80^{\circ}$.

Fourier Transform Infra-red Spectroscopy. Agilent 660-IR was used to examine the functioning groups on the $\mathrm{Cu}-\mathrm{P}$ NPs' surface. Samples for FTIR measurement were prepared by mixing $1 \%(\mathrm{w} / \mathrm{w})$ specimen with $100 \mathrm{mg}$ of $\mathrm{KBr}$ powder and pressed into a sheer slice. An average of 32 scans was collected for each measurement employing a resolution of $2 \mathrm{~cm}$. 
Thermogravimetric Analysis (TGA). The thermal stability and resistance to decomposition of the polymer were recorded on a thermogravimetric analyzer (SDT Q 600, T.A. Instruments-water LLC, Newcastle) in a temperature range of $50-900{ }^{\circ} \mathrm{C}$ under constant nitrogen flow (100 $\mathrm{mL} / \mathrm{min})$.

\section{Results and Discussion}

The Picture 1 shows the synthesized $\mathrm{Cu}-\mathrm{P}$ NPs in paste state by centrifuging after synthesis and dry powder, which was exposed in air for $24 \mathrm{~h}$. They have brown colour, which are different from the black colour of $\mathrm{CuO}$, and red colour of $\mathrm{Cu}_{2} \mathrm{O}$. It indicated the synthesized material may be not the $\mathrm{CuO}$ and $\mathrm{Cu}_{2} \mathrm{O}$.

SEM. In Figure 1 the SEM images revealed the status of $\mathrm{Cu}-\mathrm{P}$ NPs in states of colloid. The NPs in colloid were in range of $80-900 \mathrm{~nm}$ spherical particles capped by plant organic matters. The Figure 2 image showed that the powder become crystals after exposure in the air for $24 \mathrm{~h}$. According to our previous study [14] about iron-polyphenols NPs, their sizes and appearance can be determined by reagent concentration, type of polyphenols and temperature. This result could be also applied for copper-polyphenols NPs. 
XANES and EXAFS Analysis. The $\mathrm{Cu}$ K-edge XANES analysis is used in this work to determine the average $\mathrm{Cu}$ valence state in the $\mathrm{Cu}-\mathrm{P}$ NPs sample. The energy position of the $\mathrm{Cu}$ K-edge in $\mathrm{Cu}-\mathrm{P}$ NPs sample is close to the edge position of the $\mathrm{Cu}^{2+}$ compounds (Figure 3), confirming that the copper in the sample is predominantly divalent ion. At the same time, we can clearly see that the curve of $\mathrm{Cu}-\mathrm{P}$ NPs is none of the model samples, indicating that $\mathrm{Cu}-\mathrm{P}$ NPs have different molecular structure from these model coppercontaining materials.

The EXAFS simulations suggested that $\mathrm{Cu}$ K-edge EXAFS analysis is used to directly probe the local structure around $\mathrm{Cu}$ cation in the $\mathrm{Cu}-\mathrm{P}$ NPs. In the Fourier transform magnitude of the EXAFS spectrum (Figure 4), three distinct peaks are observed representing the contributions of photoelectron scattering on the nearest shells of neighbors around the $\mathrm{Cu}$ atom. Three variable parameters for each shell of neighbors are introduced in the model: the shell coordination number $(N)$, the distance $(R)$ and the Debye-Waller factor $\left(\sigma^{2}\right)$. A good agreement between the model and experimental spectrum is found using the $R$ range from 0 to $5 \AA$. The list of best fit parameters is given in Table 1. One oxygen atom is identified in the fit of the $\mathrm{Cu}-\mathrm{O}$ distance of $1.46 \AA$, which is different from the $\mathrm{Cu}-\mathrm{O}$ distances of $\mathrm{CuO}$ and $\mathrm{Cu}_{2} \mathrm{O}$ as reported [15]。 This result indicated that the synthesized material has different molecular structure with $\mathrm{CuO}$ and 
$\mathrm{Cu}_{2} \mathrm{O}$. Relatively large Debye-Waller factors for the $\mathrm{Cu}$ coordination shell indicate large disorder in the structure. The XANES and EXAFS results indicated that the synthesized material is a kind of copper oxide, but has different molecular structure with $\mathrm{Cu}_{2} \mathrm{O}$ and $\mathrm{CuO}$ due to chelating bond formed between copper ion and oxygen atom from polyphenol molecule. Guo et al. [16] assumed that $\mathrm{Cu}^{2+}$ ions can react with tannic acid to form a phenolic network capsule with Energy-dispersive X-ray elemental mapping. Our research [17] revealed that the phenolic network containing metal ions, oxygen and carbon atoms takes place due to condensation of polyphenols when adding metal ions in them, which results in losing water molecule between polyphenol molecules. It is well known that chelation takes place between metal ions and organic matter. Our works [18] have proven that the chelation between metal ions and organic matter can form nanoparticles. We found that plant polyphenols can reduce gold and silver salts in solution to pure gold and silver nanoparticles, but can only chelate copper and other metal elements, which have higher reducing potentials [17]. Therefore, the synthesized material may be called copper-polyphenol chelating complex nanoparticles.

X-ray Diffraction. The XRD patterns of the $\mathrm{Cu}-\mathrm{P}$ NPs paste did not show distinct diffraction peaks, suggesting that the material is amorphous (Figure 5). The dry powder showed typical crystal XRD patterns which don't consist with any pure crystal material 
(Figure 6). This means the powder is heterogeneous material. It is assumed that plant polyphenols capped the regent $\mathrm{CuSO}_{4}$ solution by hydrogen bond, formed amorphous molecular structure, and changed the bond connections among $\mathrm{Cu}^{2+}$ and $\mathrm{SO}_{4}{ }^{2-}$ in some degree. After $24 \mathrm{~h}$ drying in air, the $\mathrm{Cu}-\mathrm{P}$ NPs were oxidized and became crystals.

Fourier Transform Infra-red Spectroscopy. Figure 7 illustrates the FTIR spectrum of the $\mathrm{Cu}-\mathrm{P}$ NPs powder sample, revealing several peaks in the spectral range 1000-4000 $\mathrm{cm}^{-1}$. The peak at $3430 \mathrm{~cm}^{-1}$ is attributed to $\mathrm{O}-\mathrm{H}$ of the $\mathrm{H}$ bond or carboxylic acid. The feature around $1640 \mathrm{~cm}^{-1}$ presumably corresponds to the $\mathrm{O}-\mathrm{H}$ of carboxylic acids. The peak around $1200 \mathrm{~cm}^{-1}$ and $1160 \mathrm{~cm}^{-1}$ can be attributed to the $\mathrm{C}-\mathrm{O}$ of carboxylic acid. All these features indicated this dry powder nanomaterial is capped by organic matter. This outcome agrees with the results of XAS and XRD investigations.

Thermogravimetric Analysis (TGA). The thermal stability of the polycopper sulphate NPs was determined by thermogravimetric analysis. The TGA profile of the NPs indicated a two-step mass loss: almost $88 \%$ of total mass was lost in the temperature range up to $95^{\circ} \mathrm{C}$. This may be attributed to water loss due to the porous structure of the material, which can contain large amount of water. The mass percentage was reduced from $12 \%$ to $4.2 \%$ gradually with temperature increase from 96 to $900{ }^{\circ} \mathrm{C}$. It is assumed that organic 
matter chelated with copper ions was removed with increasing temperature. The residue may be copper oxide. This phenomenon suggested that the synthesized nanoparticles have big surface area, which can adsorb large amount of water, organic matter or other substances.

Antibacterial activity studies. The antibacterial activity of $\mathrm{Cu}-\mathrm{P}$ NPs was carried out on human pathogenic Escherichia coli, by standard disc diffusion method. Mueller Hinton agar medium was used to cultivate bacteria. Standard antibiotic dis $(100 \mu \mathrm{g} / \mathrm{ml})$ Ampicilin was used as reference drug and plant extract used as a control. A clear 100\% inhibition zone has been found after adding of $\mathrm{Cu}-\mathrm{P}$ NPs into the cultivated Escherichia coli. This means that the synthesized $\mathrm{Cu}-\mathrm{P}$ NPs were highly effective in their activity against these bacteria, because the released copper ions from the $\mathrm{Cu}-\mathrm{P}$ NPs the cause the membrane to rupture and kill bacteria.

\section{Conclusions}

The characterization of $\mathrm{Cu}-\mathrm{P}$ NPs using Cinnamomum pedunculatum leaves has been demonstrated. The XANES and EXAFS results indicated that the synthesized material is a kind of copper oxide, but has different molecular structure with its reagent $\mathrm{CuSO}_{4}$ and the conventional copper oxides such as $\mathrm{Cu}_{2} \mathrm{O}$ and $\mathrm{CuO}$. The XRD and FTIR results 
suggested that the synthesized materials are chelated and capped with plant polyphenols.

Therefore, it can be supposed that heterogeneous copper-polyphenols complex nanoparticles were formed. TGA pattern showed that the $\mathrm{Cu}-\mathrm{P}$ NPs contain $88 \%$ water and up to $7.8 \%$ organic matter in weight. The nanoparticles showed a clear anti Escherichia coli activity. This green synthesis approach provided a route to synthesis copper-polyphenol complex nanoparticles, which may serve as nanoagent in other applications such as semiconductor, medicine, catalyst, ceramic, and sensors.

\section{References}

1. Miao, X.-M., et al., Direct electrocatalytic reduction of hydrogen peroxide based on Nafion and copper oxide nanoparticles modified Pt electrode. Journal of Electroanalytical Chemistry, 2008. 612(2): p. 157-163.

2. Salavati-Niasari, M. and F. Davar, Synthesis of copper and copper (I) oxide nanoparticles by thermal decomposition of a new precursor. Materials Letters, 2009. 63(3): p. 441-443.

3. Lanje, A.S., et al., Synthesis and optical characterization of copper oxide nanoparticles. Advances in Applied Science Research, 2010. 1(2): p. 36-40.

4. Gupta, A.K. and M. Gupta, Synthesis and surface engineering of iron oxide nanoparticles for biomedical applications. Biomaterials, 2005. 26(18): p. 39954021.

5. Qi, L., J. Ma, and J. Shen, Synthesis of copper nanoparticles in nonionic waterin-oil microemulsions. Journal of colloid and interface science, 1997. 186(2): p. 498-500.

6. Padil, V.V.T. and M. Černík, Green synthesis of copper oxide nanoparticles using gum karaya as a biotemplate and their antibacterial application. International Journal of Nanomedicine, 2013. 8: p. 889.

7. Honary, S., et al., Green synthesis of copper oxide nanoparticles using Penicillium aurantiogriseum, Penicillium citrinum and Penicillium waksmanii. Dig J Nanomater Bios, 2012. 7: p. 999-1005. 
8. Abboud, Y., et al., Biosynthesis, characterization and antimicrobial activity of copper oxide nanoparticles (CONPS) produced using brown alga extract (Bifurcaria bifurcata). Applied Nanoscience, 2014. 4(5): p. 571-576.

9. Gunalan, S., R. Sivaraj, and R. Venckatesh, Aloe barbadensis Miller mediated green synthesis of mono-disperse copper oxide nanoparticles: optical properties. Spectrochimica Acta Part A: Molecular and Biomolecular Spectroscopy, 2012. 97: p. $1140-1144$.

10. Saif Hasan, S., et al., Bacterial synthesis of copper/copper oxide nanoparticles. Journal of nanoscience and nanotechnology, 2008. 8(6): p. 3191-3196.

11. Wang, Z., Iron complex nanoparticles synthesized by eucalyptus leaves. ACS Sustainable Chemistry \& Engineering, 2013. 1(12): p. 1551-1554.

12. Wang, Z., C. Fang, and M. Megharaj, Characterization of iron-polyphenol nanoparticles synthesized by three plant extracts and their fenton oxidation of azo dye. ACS Sustainable Chemistry \& Engineering, 2014. 2(4): p. 1022-1025.

13. Ravel, B. and M. Newville, ATHENA, ARTEMIS, HEPHAESTUS: data analysis for X-ray absorption spectroscopy using IFEFFIT. Journal of synchrotron radiation, 2005. 12(4): p. 537-541.

14. Wang, Z., et al., Dye removal using iron-polyphenol complex nanoparticles synthesized by plant leaves. Environmental Technology \& Innovation, 2014. 1: p. 29-34.

15. Nimmermark, A., L. Öhrström, and J. Reedijk, Metal-ligand bond lengths and strengths: are they correlated? A detailed CSD analysis. Zeitschrift für Kristallographie-Crystalline Materials, 2013. 228(7): p. 311-317.

16. Guo, J., et al., Engineering multifunctional capsules through the assembly of metal-phenolic networks. Angewandte Chemie International Edition, 2014. 53(22): p. 5546-5551.

17. Wang, Z., C. Fang, and M. Mallavarapu, Characterization of iron-polyphenol complex nanoparticles synthesized by Sage (Salvia officinalis) leaves. Environmental Technology \& Innovation, 2015.

18. Wang, Z., et al. Removal of acid red 94 and methylene blue using iron-polyphenol nanomaterials synthesized by various plant leaves: A comparison study. in Nanoscience and Nanotechnology (ICONN), 2014 International Conference on. 2014. IEEE. 


\section{Figures and Figure Captions}

Picture 1. Synthesized $\mathrm{Cu}-\mathrm{P}$ NPs in paste state (in the big centrifuge tube) and their dry powder (in the small centrifuge tube).

Figure 1. SEM image of $\mathrm{Cu}-\mathrm{P}$ NPs in colloid.

Figure 2. SEM image of dry $\mathrm{Cu}-\mathrm{P}$ NPs powder.

Figure 3. XANES spectrum of $\mathrm{Cu}-\mathrm{P}$ NPs.

Figure 4. EXAFS spectrum of Cu-P NPs. Experimental (solid line); theoretical (dots).

Figure 5. XRD spectrum of wet $\mathrm{Cu}-\mathrm{P}$ NPs paste.

Figure 6. XRD spectrum of dry $\mathrm{Cu}-\mathrm{P}$ NPs powder.

Figure 7. FTIR spectrum of $\mathrm{Cu}-\mathrm{P}$ NPs.

Figure 8. TG spectrum of $\mathrm{Cu}-\mathrm{P}$ NPs.

Table 1. Structural parameters $R(\AA), C N$ and $\sigma(\AA)$ derived from the EXAFS data analysis of the Fe-P NPs. $(R-$ interatomic distance; $C N$ - coordination number; $\sigma-$ Debye-Waller factor) 
bioRxiv preprint doi: https://doi.org/10.1101/134940; this version posted May 7, 2017. The copyright holder for this preprint (which was not certified by peer review) is the author/funder, who has granted bioRxiv a license to display the preprint in perpetuity. It is made available under aCC-BY 4.0 International license.

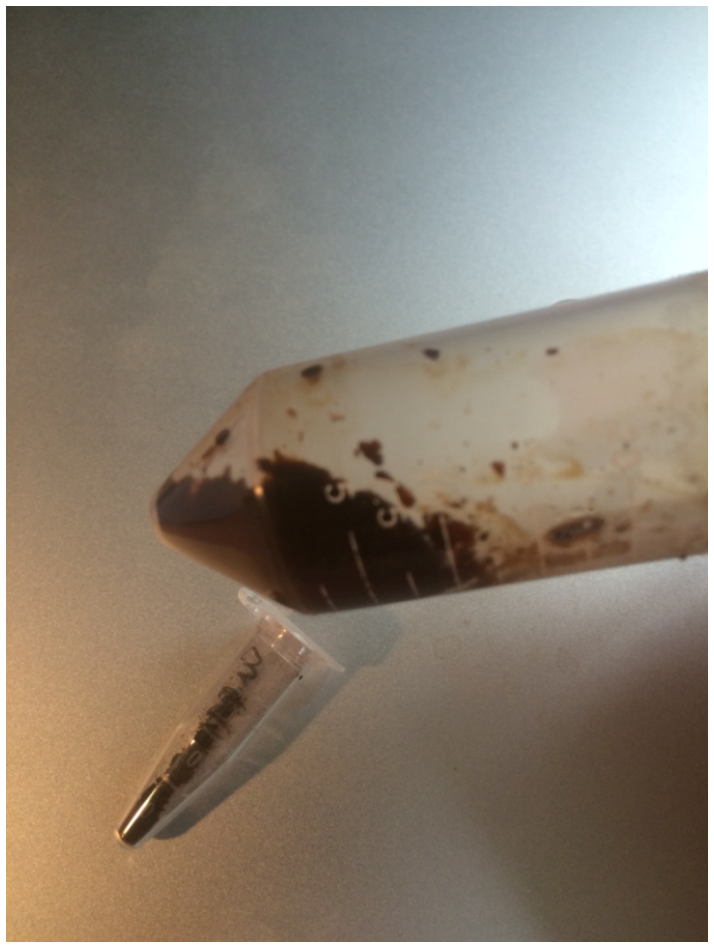

\section{Picture 1.}

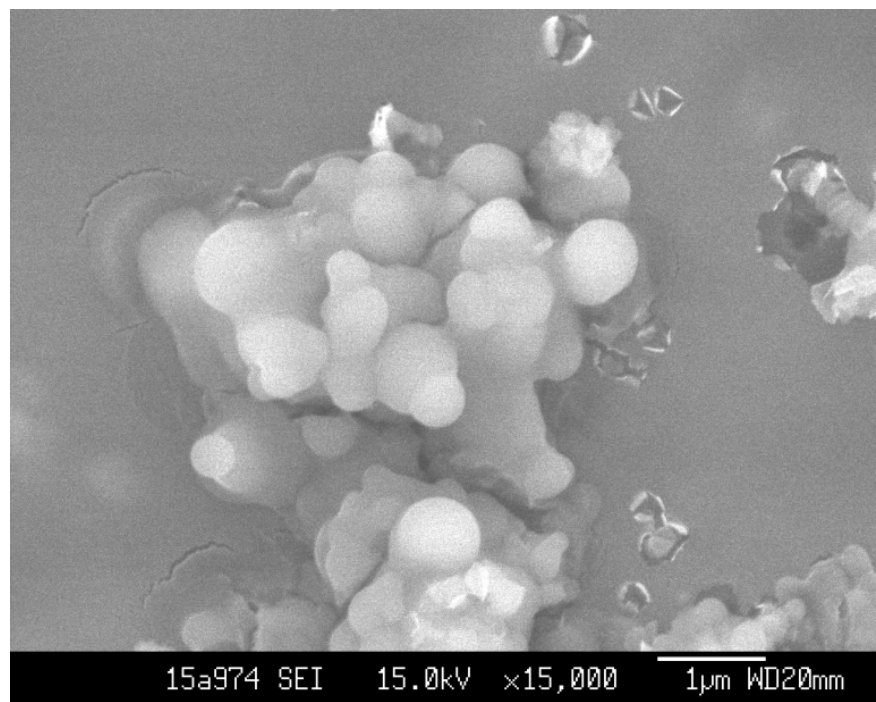

Figure 1. 


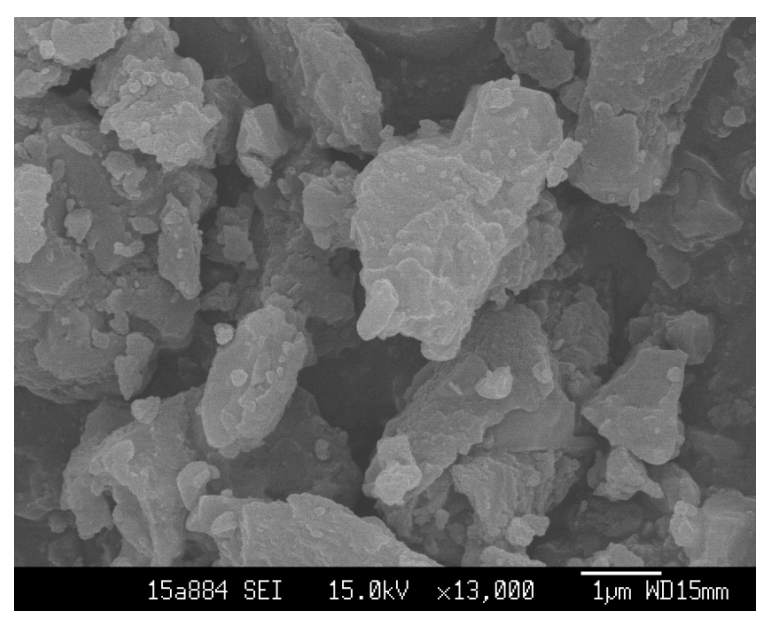

Figure 2.

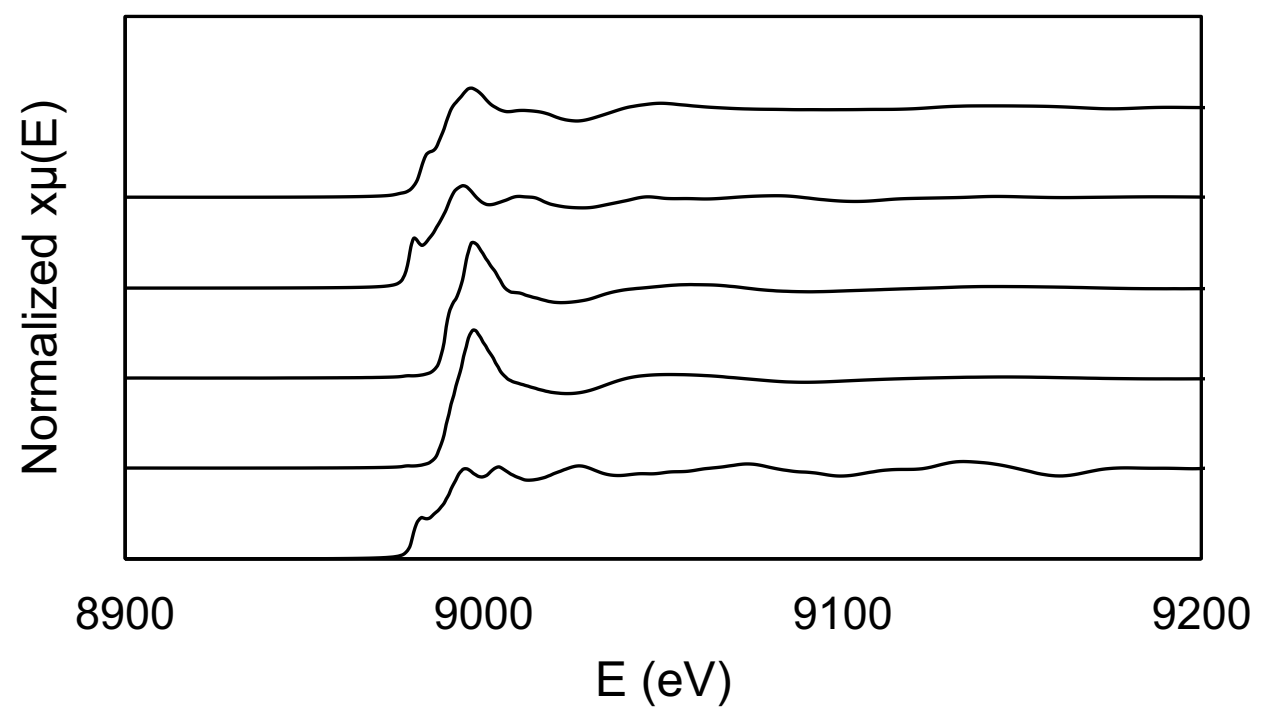

Figure 3. 


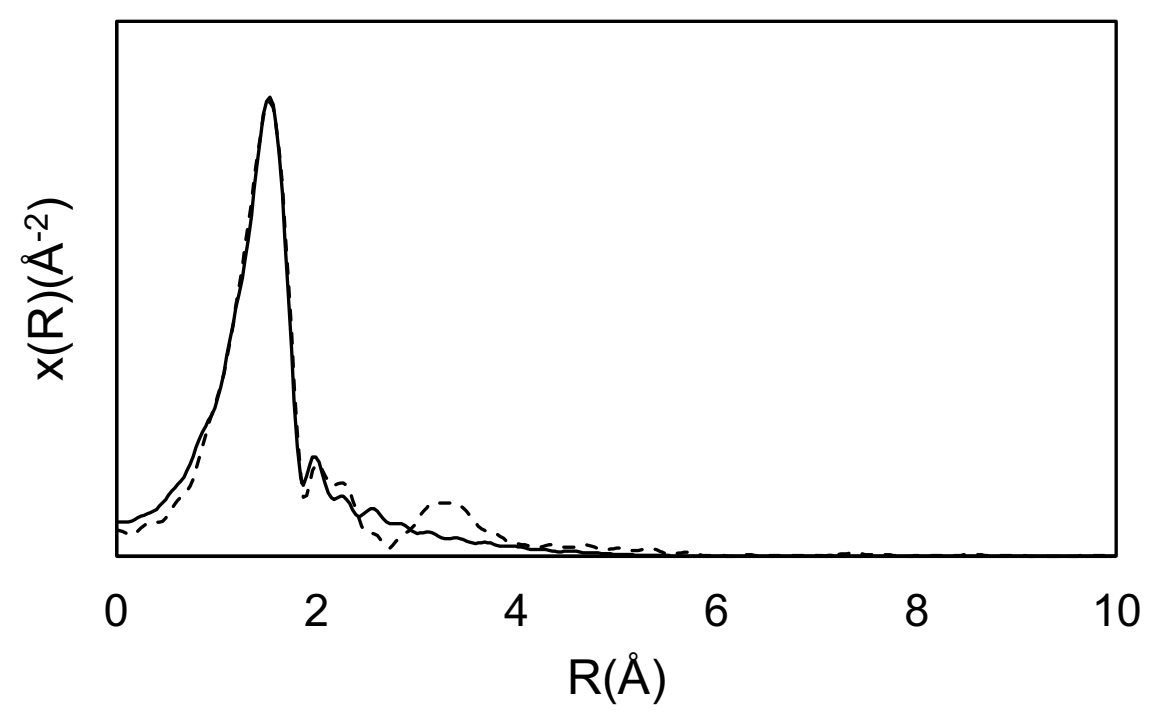

Figure 4.

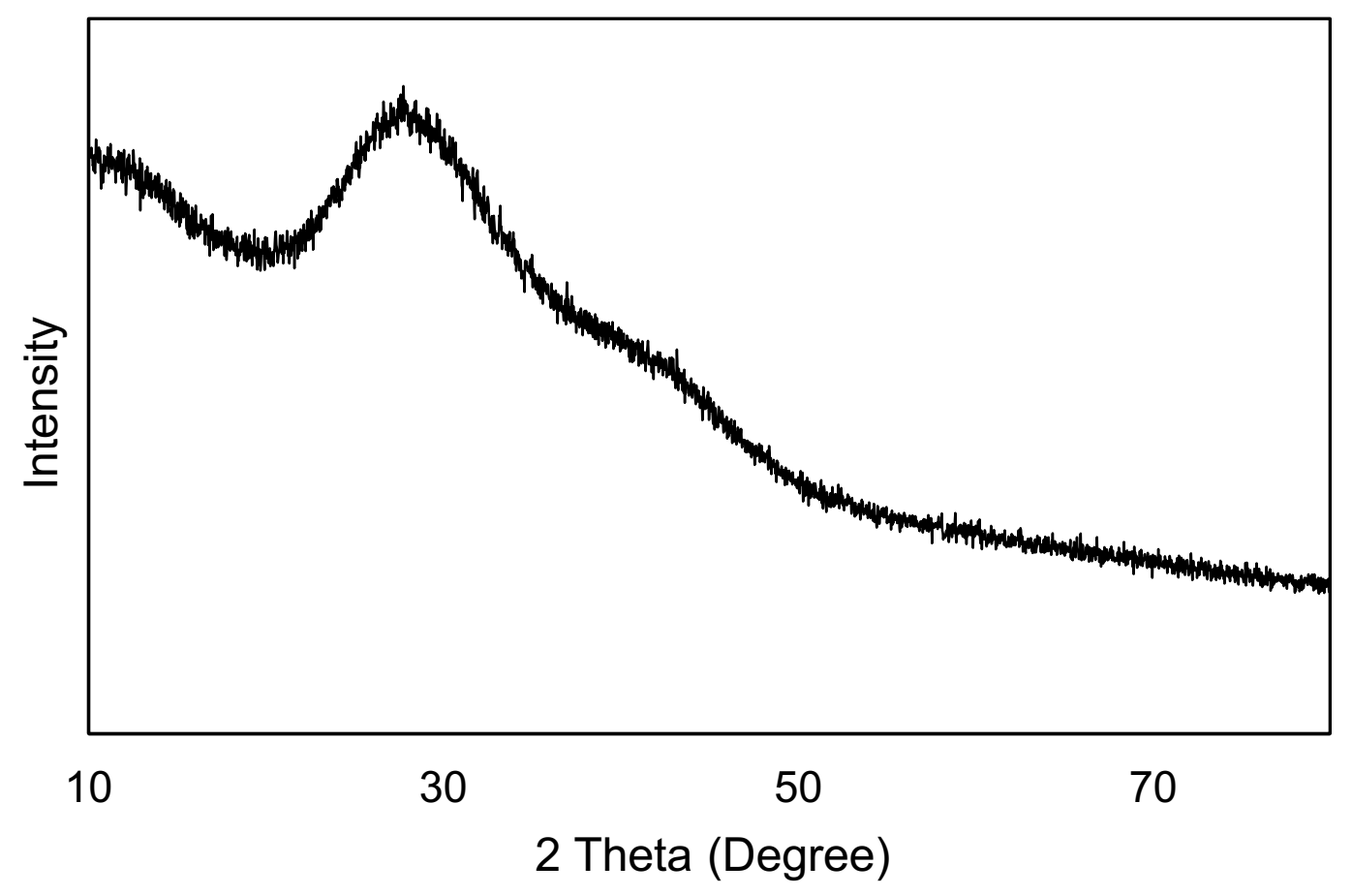

Figure 5. 


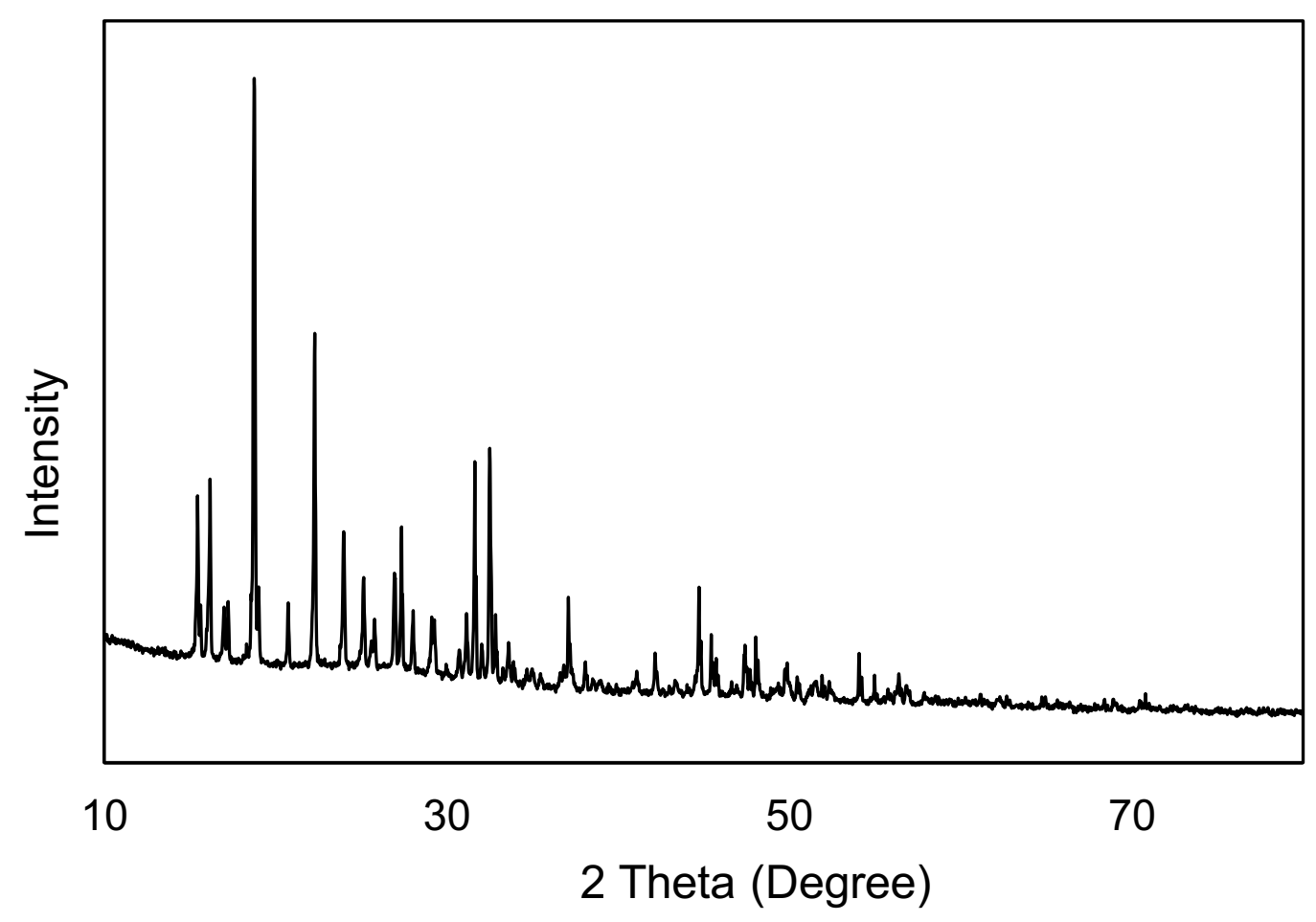

Figure 6.

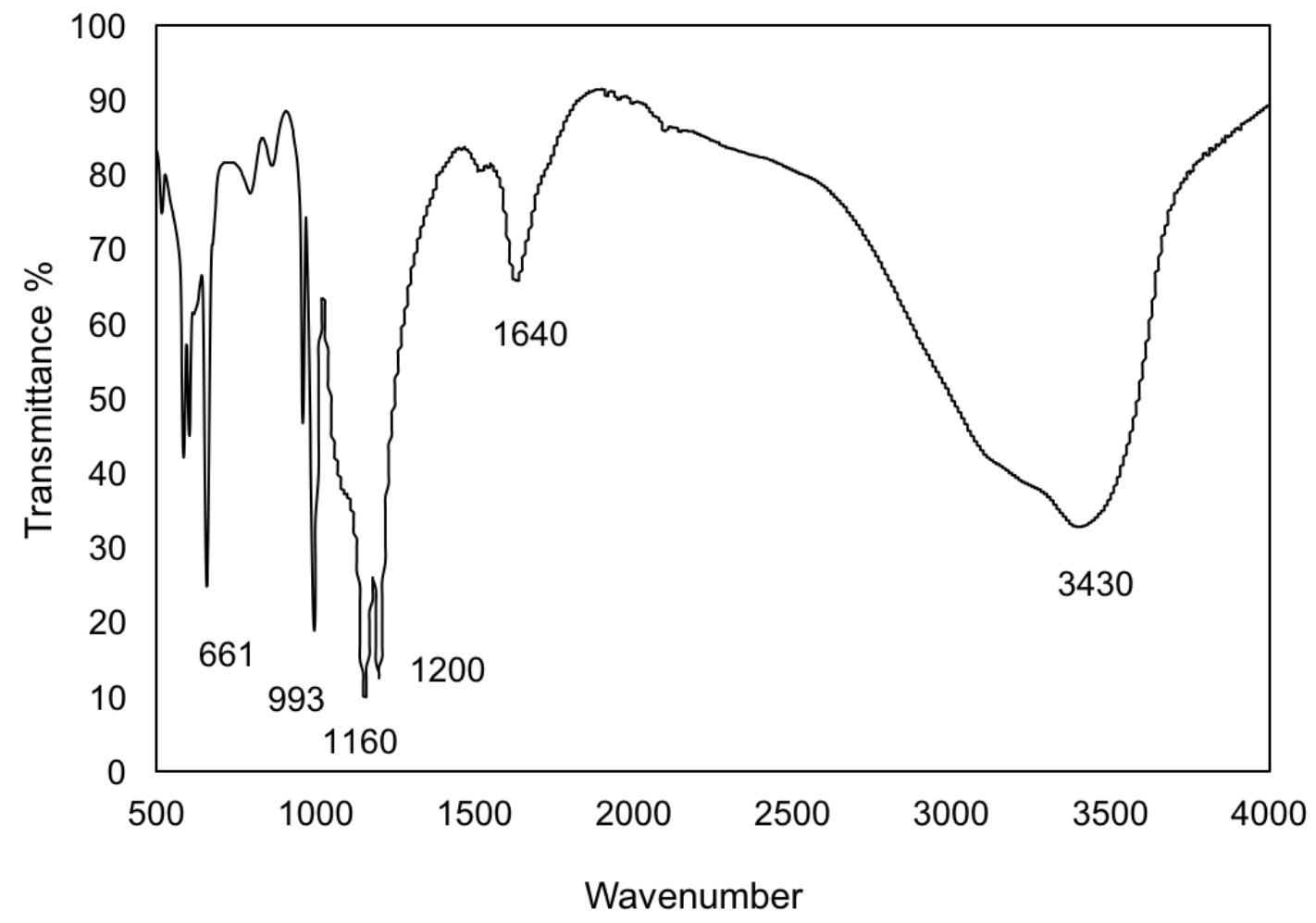

Figure 7. 
bioRxiv preprint doi: https://doi.org/10.1101/134940; this version posted May 7, 2017. The copyright holder for this preprint (which was not certified by peer review) is the author/funder, who has granted bioRxiv a license to display the preprint in perpetuity. It is made available under aCC-BY 4.0 International license.

18

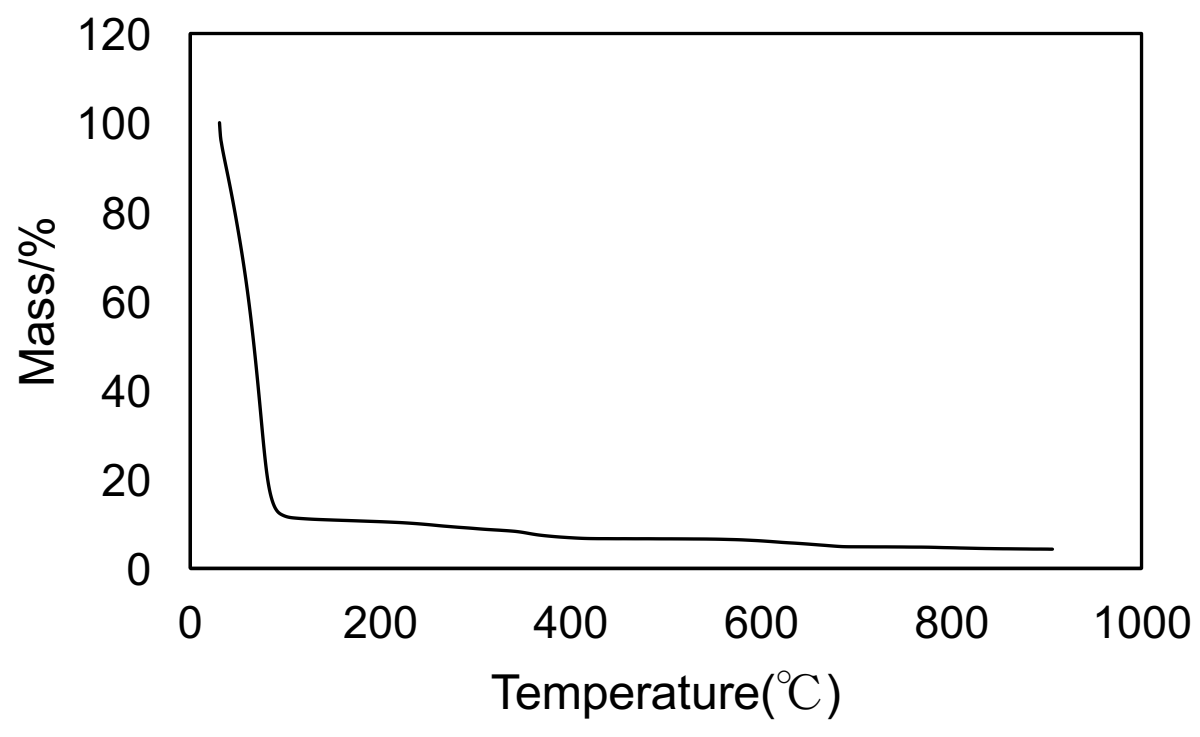

Figure 8.

Table 1.

\begin{tabular}{llll}
\hline Bond & $\mathrm{R}(\AA)$ & $\mathrm{N}$ & $\sigma^{2}\left(\AA^{2}\right)$ \\
\hline $\mathrm{Cu}-\mathrm{O}$ & 1.46 & 1 & 0.004 \\
\hline
\end{tabular}

